\title{
Cancer incidence attributable to excess body weight in Alberta in 2012
}

\author{
Darren R. Brenner PhD, Abbey E. Poirier MSc, Anne Grundy PhD, Farah Khandwala MSc, \\ Alison McFadden BSc, Christine M. Friedenreich PhD
}

\section{Abstract}

Background: Excess body weight has been consistently associated with colorectal, breast, endometrial, esophageal, gall bladder, pancreatic and kidney cancers. The objective of this analysis was to estimate the proportion of total and site-specific cancers attributable to excess body weight in adults in Alberta in 2012.

Methods: We estimated the proportions of attributable cancers using population attributable risk. Risk estimates were obtained from recent meta-analyses, and exposure prevalence estimates were obtained from the Canadian Community Health Survey. People with a body mass index of $25.00-29.99 \mathrm{~kg} / \mathrm{m}^{2}$ and of $30 \mathrm{~kg} / \mathrm{m}^{2}$ or more were categorized as overweight and obese, respectively.

Results: About $14 \%-47 \%$ of men and $9 \%-35 \%$ of women in Alberta were classified as either overweight or obese; the proportion increased with increasing age for both sexes. We estimate that roughly $17 \%$ and $12 \%$ of obesity-related cancers among men and women, respectively, could be attributed to excess body weight in Alberta in 2012. The heaviest absolute burden in terms of number of cases was seen for breast cancer among women and for colorectal cancer among men. Overall, about $5 \%$ of all cancers in adults in Alberta in 2012 were estimated to be attributable to excess body weight in 2000-2003.

Interpretation: Excess body weight contributes to a substantial proportion of cases of cancers associated with overweight and obesity annually in Alberta. Strategies to improve energy imbalance and reduce the proportion of obese and overweight Albertans may have a notable impact on cancer incidence in the future.

T n 2002, the International Agency for Research on Cancer's handbook on weight control and physical activity concluded that overweight and obesity are related to cancers of the colon, endometrium, kidney and esophagus (adenocarcinomas) as well as postmenopausal breast cancer. ${ }^{1}$ In 2007, a report by the World Cancer Research Fund Panel on Food, Nutrition, Physical Activity and the Prevention of Cancer concluded that there was also convincing evidence for associations between overweight and obesity and cancers of the pancreas and ovary as well as a probable association with cancers of the gall bladder. ${ }^{2}$ Substantial research has evaluated the association between excess body weight and risk of cancer at various sites. The global burden of cancer attributable to high body mass index (BMI) $\left(\geq 25 \mathrm{~kg} / \mathrm{m}^{2}\right)$ in 2012 was estimated to be 3.6\%. In the United Kingdom, Parkin and Boyd ${ }^{4}$ estimated that $5.5 \%$ of all incident cancers in 2010 were attributable to excess body weight. Based on these efforts, it was determined that sites with the most consistent associations were breast (postmenopausal), colon, esophagus (adenocarcinoma), kidney, endometrium, gall bladder and pancreas. ${ }^{4}$

In Alberta in 2012, 3.2\% (5044 cases) of incident cancer cases occurred at the 7 sites shown to be associated with over- weight and obesity. ${ }^{5}$ We previously estimated that $2.6 \%$ and $4.6 \%$ of cancers among men and women, respectively, in Canada could be attributed to excess body weight (BMI $>25) .{ }^{6} \mathrm{We}$ did not, however, estimate the number or proportion of cancer cases attributable to excess body weight at the provincial level, and we suspected that there might be substantial variation across provinces because of cross-provincial differences in prevalence of excess body weight. The purpose of this analysis was to estimate the proportion of incident cancers that occurred in Alberta in 2012 that were attributable to overweight and obesity. We included the 7 cancer sites previously shown to be positively associated with overweight/obesity (as described above) in our population attributable risk estimations for comparability of methods and results.

Competing interests: None declared.

This article has been peer reviewed.

Correspondence to: Darren.Brenner@albertahealthservices.ca

CMAJ Open 2017. DOI:10.9778/cmajo.20160039 


\section{Methods}

This paper is part of a series of exposure-specific manuscripts concerning the proportion of cancer cases attributable to modifiable lifestyle and environmental risk factors in the general population of Alberta. The methodologic framework for this series' methods has been previously described.?

\section{Cancer incidence data}

To determine the number of cancer cases attributable to excess body weight in Alberta, we obtained age-, sex- and sitespecific cancer incidence strata for 2012 from the Alberta Cancer Registry. We created age and sex incidence strata to match the strata available for the data on overweight/obesity prevalence. We used the year with the most up-to-date complete data (2012) for all cancer sites available.

For esophageal cancer, we included only the number of adenocarcinomas diagnosed in 2012 in our attributable case estimates, since only adenocarcinomas are consistently associated with overweight/obesity. In this population, 67\% and $41 \%$ of esophageal cancers were adenocarincomas in men and women, respectively. We used this approach because information on histology by cancer site was not available for these analyses. We included only breast cancers in postmenopausal women in attributable estimates by including breast cancers that occurred after 55 years of age, as the median age at menopause among North American women is 50-52 years.,

\section{Latency period}

The effect of obesity on cancer risk is understood to be the result of past exposure. Therefore, we identified a biologically meaningful latency period of 10-12 years between exposure and subsequent cancer from previous prospective cohort studies (Table 1). As has been previously described, ${ }^{7}$ we considered the theoretical latency period to be the time between initiation of exposure and cancer diagnosis, and the measured latency period to be the time between exposure measurement and cancer diagnosis. We estimated a 10- to 12-year latency period by applying the estimates of exposure prevalence in 2000-2003 to cases that occurred in 2012 and assuming that

Table 1: Predetermined latency periods for calculations of population attributable risk for overweight/obesity, by cancer site and CCHS cycle of prevalence data used

\begin{tabular}{|lcc|}
\hline Cancer site & Latency period, yr & $\begin{array}{c}\text { Corresponding CCHS } \\
\text { cycle (yr) }\end{array}$ \\
\hline Esophagus & $11-12$ & $1.1(2000-2001)$ \\
\hline Pancreas & 9 & $2.1(2003)$ \\
\hline Colorectum & 9 & $2.1(2003)$ \\
\hline Kidney & $11-12$ & $1.1(2000-2001)$ \\
\hline Gall bladder & $11-12$ & $1.1(2000-2001)$ \\
\hline Breast & 9 & $2.1(2000-2001)$ \\
\hline Endometrium & $11-12$ & $1.1(2000-2001)$ \\
\hline Note: CCHS = Canadian Community Health Survey. & \\
\hline
\end{tabular}

people exposed in 2000-2003 would have transitioned into the subsequent 10-year cancer incidence group by the time of diagnosis. We obtained data from the Canadian Community Health Survey (CCHS) to estimate the prevalence of overweight and obese among adults in Alberta. The cycle of the CCHS used corresponded to the midpoint of the latency period suggested by prospective cohort studies for each cancer site of interest (Table 1).

\section{Prevalence of exposure}

We estimated BMI for the Alberta population aged 18 years or more (excluding pregnant women and people less than $0.9 \mathrm{~m}$ tall or greater than $2.11 \mathrm{~m}$ tall) using CCHS data. The $\mathrm{BMI}$ of survey respondents was based on the questions "How much do you weigh?" and "How tall are you without shoes on?" Cut-points were used according to Health Canada classifications for body weight: ${ }^{10}$ less than $18.50 \mathrm{~kg} / \mathrm{m}^{2}$ (underweight), $18.50-24.99 \mathrm{~kg} / \mathrm{m}^{2}$ (normal weight), $25.00-29.99 \mathrm{~kg} /$ $\mathrm{m}^{2}$ (overweight), $30.00-34.99 \mathrm{~kg} / \mathrm{m}^{2}$ (obese class I), 35.00 $39.99 \mathrm{~kg} / \mathrm{m}^{2}$ (obese class II) and 40.00 or greater (obese class III). The CCHS is considered representative of the general Canadian population, excluding full-time members of the Canadian Forces, people living on reserves or other Aboriginal settlements, and people living in institutions. Descriptions of the survey methods used to generate the sampling strategy for the CCHS have been published previously. ${ }^{11}$

\section{Risk estimates}

We took risk estimates used for estimating population attributable risks from the comprehensive meta-analysis of excess body weight and cancer risk by Renehan and colleagues ${ }^{12}$ (Table 2). We used estimates of relative risk (RR) for an

\begin{tabular}{|c|c|c|}
\hline Cancer site & Sex & Relative risk $(95 \% \mathrm{Cl}) \dagger$ \\
\hline \multirow[t]{2}{*}{ Esophagus } & Men & $1.52(1.33-1.74)$ \\
\hline & Women & $1.51(1.31-1.74)$ \\
\hline \multirow[t]{2}{*}{ Pancreas } & Men & $1.07(0.93-1.23)$ \\
\hline & Women & $1.12(1.02-1.22)$ \\
\hline \multirow[t]{2}{*}{ Colorectum } & Men & $1.24(1.20-1.28)$ \\
\hline & Women & $1.09(1.05-1.13)$ \\
\hline \multirow[t]{2}{*}{ Kidney } & Men & $1.24(1.15-1.34)$ \\
\hline & Women & $1.34(1.25-1.43)$ \\
\hline \multirow[t]{2}{*}{ Gall bladder } & Men & $1.09(0.99-1.21)$ \\
\hline & Women & 1.59 (1.02-2.47) \\
\hline Breast & Women & $1.12(1.08-1.16)$ \\
\hline Endometrium & Women & $1.59(1.50-1.68)$ \\
\hline \multicolumn{3}{|c|}{$\begin{array}{l}\text { Note: } \mathrm{Cl}=\text { confidence interval. } \\
{ }^{*} \text { Risk estimates from Renehan and colleagues: }{ }^{12} \text { meta-analysis of } 76 \text { studies } \\
\text { including } 67 \text { cohort studies, } 6 \text { nested case-control studies and } 3 \text { randomized } \\
\text { trials (with a total of } 282137 \text { incident cancer cases reported) published between } \\
1966 \text { and } 2007 \text {. } \\
\text { †Risk estimates are for an increase in body mass index of } 5 \mathrm{~kg} / \mathrm{m}^{2} \text {. }\end{array}$} \\
\hline
\end{tabular}


increase in BMI of $5 \mathrm{~kg} / \mathrm{m}^{2}$ for the overweight group, and, assuming a constant rate of increase in risk, this value was squared for use in the obese category.

\section{Estimation of population attributable risk}

We used the method applied by Parkin ${ }^{13}$ to estimate the proportion of incident cancer cases in Alberta associated with excess body weight. We used the following formula for the population attributable risk:

Population attributable risk $=\left(p_{1} \times E R R_{1}\right)+\left(p_{2} \times E R R_{2}\right) / 1+$ $\left[\left(p_{1} \times E R R_{1}\right)+\left(p_{2} \times E R R_{2}\right)\right]$

We estimated the population attributable risk for the different sex and age groups using the prevalence estimates of overweight/obesity according to the formula where $p_{1}$ is the proportion of the population that is overweight, $p_{2}$ the proportion of the population that is obese, $E R R_{1}$ the excess relative risk $(\mathrm{RR}-1)$ for overweight and $E R R_{2}$ the excess relative risk $(R R-1)$ for obesity. We then multiplied the population attributable risks by the incident cancer cases of interest in Alberta in 2012, obtained from the Alberta Cancer Registry, to determine the excess attributable cases for each cancer site. We backcalculated estimates of population attributable risk for men and women combined by adding the number of cases of cancer attributable to overweight/obesity in men and women and dividing by the total number of incident cancer cases at associated sites in Alberta in 2012.

To estimate $95 \%$ confidence intervals (CIs) around population attributable risk estimates, we used Monte Carlo simulation methods wherein the relative risk estimates were drawn from a $\log$ normal distribution, prevalence estimates were drawn from a binomial distribution, and incidence estimates were drawn from a Poisson distribution. Parameters for the distributions were defined by reported point estimates and CIs. A total of 10000 samples were drawn, and the 2.5th and 97.5th percentiles of the resulting population attributable risk distribution were used as the lower and upper limits of a $95 \%$ CI. Similar techniques were used in 2 previous studies that estimated population attributable risk. ${ }^{14,15}$ Wherever possible and appropriate, we performed these estimations for individual sex and age groups.

\section{Sensitivity analysis}

As data on overweight and obesity were derived from selfreported measures of BMI in the CCHS, self-report bias had to be considered. To adjust the CCHS self-reported prevalence of overweight/obesity, we conducted a sensitivity analysis. Shields and colleagues ${ }^{16}$ reported that overweight prevalence was underestimated by $1.9 \%$ among males and $3.9 \%$ among females, and obesity was underestimated by $6.4 \%$ and $6.7 \%$, respectively, in the 2008 Canadian Health Measures Survey when applied to the 2005 CCHS estimates. We applied these correction factors to the CCHS estimates for the 2000-2001 cycle to adjust for potential bias (Appendix 1, Supplementary Table 1, available at www.cmajopen.ca/ content/5/2/E330/supp1/DC1). All analyses were conducted with the use of $\mathrm{R}$ (version 3.2.3) and RStudio (version 0.98.1080) (R Studio, Inc.).

\section{Ethics approval}

Ethics approval was obtained from the Conjoint Health Research Ethics Board, University of Calgary.

\section{Results}

\section{Prevalence of excess body weight}

The prevalence of overweight and obesity in the Alberta adult population for 2000-2001 is presented in Table 3. In general, levels of both overweight and obesity were higher among older age groups, with the highest prevalence observed for those aged $65-74$. In this age group, the total population prevalence of overweight was $41.1 \%$ (95\% CI 37.3-44.9) and of obesity, $18.7 \%$ (95\% CI 15.9-21.5). When the combined prevalence of overweight and obesity was examined (data not shown), adult men had the highest prevalence of excess body weight. Among men, more than $60 \%$ of respondents in all age groups over 35 years reported a BMI of $25 \mathrm{~kg} / \mathrm{m}^{2}$ or greater.

\begin{tabular}{|c|c|c|}
\hline \multirow[b]{2}{*}{ Sex; age, yr } & \multicolumn{2}{|c|}{ Prevalence, $\%(95 \% \mathrm{Cl})$} \\
\hline & $\begin{array}{c}\text { Overweight } \\
\left(\mathrm{BMI} \geq 25 \mathrm{~kg} / \mathrm{m}^{2}\right)\end{array}$ & $\begin{array}{c}\text { Obesity } \\
\left(\mathrm{BMI} \geq 30 \mathrm{~kg} / \mathrm{m}^{2}\right)\end{array}$ \\
\hline \multicolumn{3}{|l|}{ Men } \\
\hline $18-34$ & $33.7(30.8-36.7)$ & $13.8(11.8-15.8)$ \\
\hline $35-44$ & $41.9(38.2-45.7)$ & $19.0(15.9-22.2)$ \\
\hline $45-54$ & $43.2(39.1-47.3)$ & $19.4(16.1-22.7)$ \\
\hline $55-64$ & $47.2(41.9-52.6)$ & $17.2(13.5-20.9)$ \\
\hline $65-74$ & $38.2(32.4-44.0)$ & $17.7(13.9-21.5)$ \\
\hline$\geq 75$ & $41.0(33.8-48.2)$ & $13.3(8.6-18.1)$ \\
\hline \multicolumn{3}{|l|}{ Women } \\
\hline $18-34$ & $17.2(14.8-19.6)$ & $9.3(7.7-10.9)$ \\
\hline $35-44$ & $26.6(23.4-29.8)$ & $14.7(12.1-17.2)$ \\
\hline $45-54$ & 27.7 (23.9-31.4) & $17.5(14.3-20.8)$ \\
\hline $55-64$ & $35.2(29.8-40.6)$ & $20.2(15.8-24.6)$ \\
\hline $65-74$ & $35.1(29.8-40.3)$ & $17.3(13.6-21.0)$ \\
\hline$\geq 75$ & $28.5(23.8-33.2)$ & $13.9(10.6-17.3)$ \\
\hline \multicolumn{3}{|l|}{ Total } \\
\hline $18-34$ & $25.9(24.0-27.7)$ & $11.7(10.4-12.9)$ \\
\hline $35-44$ & $34.4(31.9-36.8)$ & $16.9(14.9-18.9)$ \\
\hline $45-54$ & 35.7 (32.9-38.5) & $18.5(16.1-20.9)$ \\
\hline $55-64$ & $41.1(37.3-44.9)$ & $18.7(15.9-21.5)$ \\
\hline $65-74$ & $36.6(32.5-40.7)$ & $17.5(14.7-20.3)$ \\
\hline$\geq 75$ & 33.7 (29.4-37.9) & $13.7(10.9-16.5)$ \\
\hline
\end{tabular}




\section{Cancer-site-specific population attributable risk}

The attributable proportions of cases across different cancer sites varied widely, with the highest estimates observed for adenocarcinomas of the esophagus and endometrial cancers (24.4\%-31.8\% and $19.6 \%-34.1 \%$ across age groups, respectively). Table 4 presents the numbers and proportions of incident cancer cases attributable to overweight and obesity by age and sex groups in Alberta in 2012. Measures of uncertainty (95\% CIs) for the site-specific estimates of population attributable risk are given in Appendix 1, Supplementary Table 2. The lowest estimates of attributable proportions of cancer were observed for breast and pancreatic cancers, ranging from $6.2 \%-9.1 \%$ and $4.2 \%-7.4 \%$ across age groups, respectively. In terms of absolute number of cases, the sites most affected by excess body weight were the colorectum for men and women, and the breast for women. This higher number is a result of the greater total incidence of these cancers in the province despite a smaller population attributable risk (Figure 1).

\section{Overall population attributable risk}

The overall population attributable risks and number of excess attributable cases of each cancer type and for all associated and total cancers are presented in Table 5. A total of $13.3 \%$ of these cancers can be attributed to overweight and obesity. This number equals $4.2 \%(n=673)$ of all cancer cases in adults in Alberta in 2012. When we adjusted prevalence estimates to account for self-report bias, the proportion of incident cancers in 2012 attributable to overweight/obesity increased to $5.0 \%$ (798 excess attributable cases due to overweight and obesity/15 836 observed cases) (Appendix 1, Supplementary Table 3).

\section{Interpretation}

We have estimated that at least $4.2 \%$ of all cases of cancers in adults in Alberta in 2012 were attributable to excess body weight. These estimates also suggest that the burden of cancer

Table 4: Numbers and proportions of incident cancer cases attributable to overweight and obesity in Alberta in $2012^{\star} \dagger$

\begin{tabular}{|c|c|c|c|c|c|c|c|c|c|c|c|c|c|c|c|c|c|c|c|c|c|c|}
\hline \multirow{3}{*}{$\begin{array}{l}\text { Sex; } \\
\text { age at } \\
\text { exposure, } \\
\text { yr }\end{array}$} & \multirow{3}{*}{$\begin{array}{c}\text { Age at } \\
\text { outcome, } \\
\text { yr }\end{array}$} & \multicolumn{21}{|c|}{ Cancer site } \\
\hline & & \multicolumn{3}{|c|}{ Esophagus } & \multicolumn{3}{|c|}{ Pancreas } & \multicolumn{3}{|c|}{ Colorectum } & \multicolumn{3}{|c|}{ Kidney } & \multicolumn{3}{|c|}{ Gall bladder } & \multicolumn{3}{|c|}{ Breast } & \multicolumn{3}{|c|}{ Endometrium } \\
\hline & & Obs. & $\begin{array}{c}\text { PAR, } \\
\%\end{array}$ & EAC & Obs. & $\begin{array}{c}\text { PAR, } \\
\%\end{array}$ & EAC & Obs. & $\begin{array}{c}\text { PAR, } \\
\%\end{array}$ & EAC & Obs. & $\begin{array}{c}\text { PAR, } \\
\%\end{array}$ & EAC & Obs. & $\begin{array}{c}\text { PAR, } \\
\%\end{array}$ & EAC & Obs. & $\begin{array}{c}\text { PAR. } \\
\%\end{array}$ & EAC & Obs. & $\begin{array}{c}\text { PAR, } \\
\%\end{array}$ & EAC \\
\hline \multicolumn{23}{|l|}{ Men } \\
\hline $18-34$ & $28-44$ & $<5$ & 26.3 & $<5$ & 5 & 4.2 & 0 & 39 & 13.4 & 5 & 28 & 13.4 & 4 & 0 & 5.3 & 0 & & & & & & \\
\hline $35-44$ & $45-54$ & 20 & 31.8 & 6 & 19 & 5.4 & 1 & 125 & 16.8 & 21 & 56 & 16.9 & 9 & $<5$ & 6.8 & $<5$ & & & & & & \\
\hline $45-54$ & $55-64$ & 38 & 32.4 & 12 & 33 & 5.8 & 2 & 301 & 18.1 & 54 & 109 & 17.2 & 19 & $<5$ & 7.0 & $<5$ & & & & & & \\
\hline $55-64$ & $65-74$ & 25 & 32.0 & 8 & 50 & 5.6 & 3 & 304 & 17.6 & 54 & 79 & 17.1 & 13 & 6 & 7.0 & $<5$ & & & & & & \\
\hline $65-74$ & $75-84$ & 17 & 30.1 & 5 & 48 & 5.6 & 3 & 264 & 17.3 & 46 & 48 & 15.7 & 8 & 12 & 6.3 & 1 & & & & & & \\
\hline$\geq 75$ & $\geq 85$ & 6 & 27.9 & 2 & 17 & 4.6 & 1 & 74 & 14.4 & 11 & 6 & 14.5 & 1 & $<5$ & 5.8 & $<5$ & & & & & & \\
\hline Total & & $<111$ & & $<38$ & 172 & & 9 & 1107 & & 191 & 326 & & 54 & 24 & & 2 & & & & & & \\
\hline \multicolumn{23}{|l|}{ Women } \\
\hline $18-34$ & $28-44$ & $<5$ & 17.1 & $<5$ & $<5$ & 4.5 & 0 & 37 & 3.4 & 1 & 14 & 11.7 & 2 & $<5$ & 19.6 & $<5$ & & & & 26 & 19.6 & 5 \\
\hline $35-44$ & $45-54$ & $<5$ & 24.5 & $<5$ & 26 & 5.8 & 1 & 108 & 4.4 & 5 & 28 & 17.2 & 5 & $<5$ & 27.6 & $<5$ & & & & 83 & 27.6 & 23 \\
\hline $45-54$ & $55-64$ & 6 & 26.8 & 2 & 42 & 7.1 & 3 & 179 & 5.4 & 10 & 41 & 18.9 & 8 & 7 & 30.1 & 2 & 577 & 7.1 & 41 & 195 & 30.1 & 59 \\
\hline 55-64 & $65-74$ & $<5$ & 30.5 & $<5$ & 54 & 9.1 & 5 & 198 & 6.9 & 14 & 40 & 21.9 & 9 & 9 & 34.1 & 3 & 541 & 9.1 & 49 & 127 & 34.1 & 43 \\
\hline $65-74$ & $75-84$ & 0 & 28.6 & 0 & 60 & 8.4 & 5 & 214 & 6.4 & 14 & 22 & 20.4 & 4 & 8 & 32.0 & 3 & 321 & 8.4 & 27 & 55 & 32.0 & 18 \\
\hline$\geq 75$ & $\geq 85$ & 0 & 24.4 & 0 & 25 & 6.2 & 2 & 112 & 4.7 & 5 & 11 & 17.2 & 2 & $<5$ & 27.6 & $<5$ & 106 & 6.2 & 7 & 18 & 27.6 & 5 \\
\hline Total & & $<15$ & & $<5$ & $<212$ & & 16 & 848 & & 48 & 156 & & 29 & 31 & & 10 & 1545 & & 124 & 504 & & 153 \\
\hline \multicolumn{23}{|l|}{ Total } \\
\hline $18-34$ & $28-44$ & 5 & 24.4 & 1 & $<10$ & 4.2 & 0 & 76 & 8.5 & 6 & 42 & 12.8 & 5 & $<5$ & 19.6 & $<5$ & & & & 26 & 19.6 & 5 \\
\hline $35-44$ & $45-54$ & $<25$ & 30.6 & $<10$ & 45 & 5.6 & 3 & 233 & 11.1 & 26 & 84 & 17.0 & 14 & $<10$ & 20.7 & $<5$ & & & & 83 & 27.6 & 23 \\
\hline $45-54$ & $55-64$ & 44 & 31.3 & 14 & 75 & 6.6 & 5 & 480 & 13.4 & 64 & 150 & 17.7 & 27 & $<12$ & 25.0 & 2 & 577 & 7.1 & 41 & 195 & 30.1 & 59 \\
\hline $55-64$ & $65-74$ & $<30$ & 31.8 & $<10$ & 104 & 7.4 & 8 & 502 & 13.4 & 67 & 119 & 18.7 & 22 & 15 & 23.2 & 3 & 541 & 9.1 & 49 & 127 & 34.1 & 43 \\
\hline $65-74$ & $75-84$ & 17 & 29.9 & 5 & 108 & 7.1 & 8 & 478 & 12.4 & 59 & 70 & 17.2 & 12 & 20 & 16.6 & 3 & 321 & 8.4 & 27 & 55 & 32.0 & 18 \\
\hline$\geq 75$ & $\geq 85$ & 6 & 27.0 & 2 & 42 & 5.6 & 2 & 186 & 8.6 & 16 & 17 & 16.2 & 3 & $<5$ & 16.7 & $<5$ & 106 & 6.2 & 7 & 18 & 27.6 & 5 \\
\hline Total & & 123 & & 38 & $<384$ & & 25 & 1955 & & 239 & 482 & & 83 & 55 & & 11 & 1545 & & 124 & 504 & & 153 \\
\hline
\end{tabular}




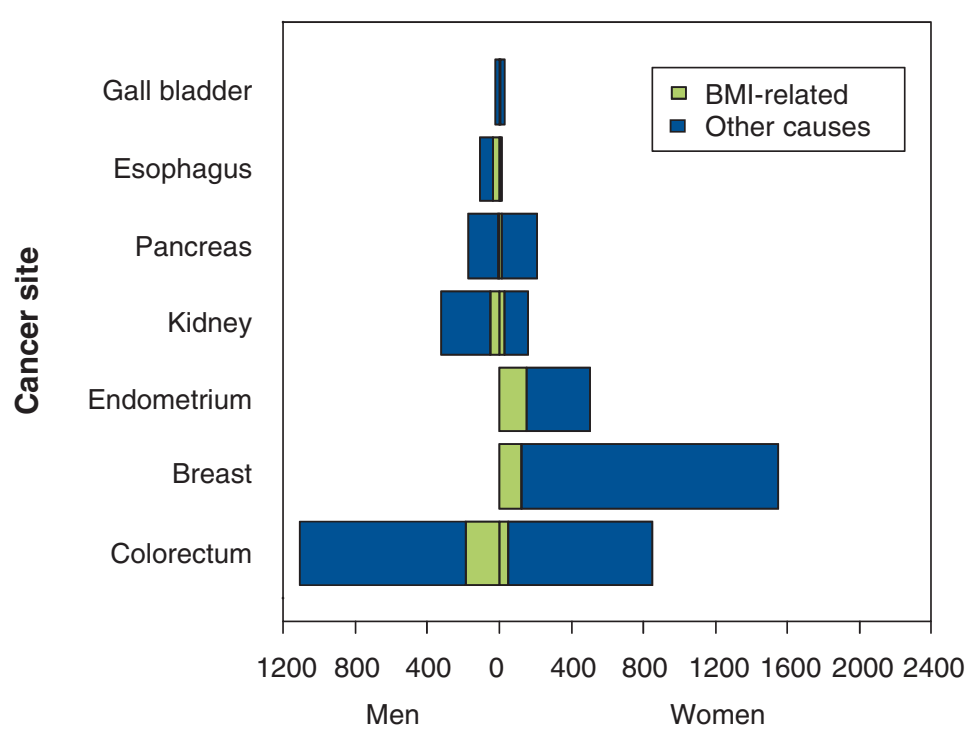

No. of cases

Figure 1: Number of cancer cases attributable to overweight/obesity and other causes in Alberta in 2012. BMI = body mass index.

incidence attributable to this risk factor is greater among women in Alberta, with larger absolute and relative numbers of cases among women attributable to both overweight and obesity.

Our site-specific estimates are comparable to previous estimates in Canada. Brenner ${ }^{6}$ estimated that $26.6 \%$ of endometrial, $7.5 \%$ of breast, $9.8 \%$ of colon, $15.6 \%$ of esophageal, $19.0 \%$ of kidney, $14.2 \%$ of gall bladder and $9.2 \%$ of pancreatic cancers in Canadians in 2007 could be attributed to overweight/obesity. Luo and colleagues ${ }^{17}$ estimated that $22.1 \%$ of endometrial, $12.1 \%$ of breast and $9.5 \%$ of colon cancers in adults aged 20 or more could be attributed to obesity in Canada. Those authors used 6 national population-based health surveys conducted between 1970 and 2004, including the 2004 CCHS, to obtain data on BMI. The surveys covered the 10 Canadian provinces. Their estimates are similar to the rates of $30.3 \%, 8.0 \%$ and $12.2 \%$ that we found for the same cancer sites in the current analysis. Using data for women aged 50-69 years between 1994 and 2006 from the National Population Health Survey in Canada for BMI estimates, Neutel and Morrison ${ }^{18}$ estimated that $8.8 \%$ of breast cancers in 2006 could be attributed to obesity.

In terms of overall attributable burden, our analyses are directly comparable to the work of Parkin, ${ }^{4}$ who examined the same cancer sites that we did and estimated that, in the United Kingdom in 2010, $5.5 \%$ of all cancers could be attributed to excess body weight, compared with $4.2 \%$ estimated in our analysis. In Australia, 3.4\% of incident cancer cases in 2010 were estimated to be attributable to overweight/obesity. ${ }^{19}$ In addition to the sites included in the UK analysis and our analysis, the Australian study included ovarian cancer. The lower population attributable risk estimate in the Australian study is likely due to the lower prevalence of overweight and obesity in Australia compared to Alberta. Congruent with our analyses, the population attributable risks estimates were highest for esophageal and endometrial cancer in the UK and Australian studies. ${ }^{4,19}$

In the global burden of cancer study, it was estimated that $3.8 \%$ and $7.9 \%$ of cancer cases in Canada could be attributable to a BMI of $25 \mathrm{~kg} / \mathrm{m}^{2}$ or higher in men and women, respectively. ${ }^{3}$ Although the estimate for Canadian men was similar to ours in Alberta, the estimate for women was higher than our estimate of $5.0 \%$. However, the global analysis used prevalence estimates only from the United States in their North American (US and Canada) estimates, and therefore the difference in estimates is likely due to a higher prevalence of overweight/obesity in the US than in Alberta. In addition, on a global scale, it was estimated that $25 \%$ of cancer cases related to high BMI in 2012 could have been avoided if the global distribution of BMI from 1982 had remained. ${ }^{3}$

\section{Limitations}

Our analyses are limited by the use of self-reported data for exposure prevalence estimates. Validation of Canadian data has shown self-reported measures to underestimate the prevalence of obesity by $4 \%-7 \% .{ }^{20}$ When we used adjusted prevalence estimates for overweight and obesity, the proportion of incident cancers attributable to overweight/obesity increased from $4.2 \%$ to $5.0 \%$. These analyses may also be limited since we excluded cancer sites for which the evidence of an etiologic role of obesity is only suggestive. The cancers not considered were thyroid cancer, ${ }^{21}$ ovarian cancer, ${ }^{22}$ malignant melanoma (in men only), ${ }^{23}$ leukemia, non-Hodgkin lymphoma and 


\begin{tabular}{|c|c|c|c|c|c|c|c|c|c|}
\hline \multirow[b]{2}{*}{ Cancer site } & \multicolumn{3}{|c|}{ Total } & \multicolumn{3}{|c|}{ Men } & \multicolumn{3}{|c|}{ Women } \\
\hline & $\begin{array}{l}\text { No. of } \\
\text { observed } \\
\text { cases }\end{array}$ & $\begin{array}{c}\text { No. of excess } \\
\text { attributable } \\
\text { cases* }^{*}\end{array}$ & $\%$ & $\begin{array}{l}\text { No. of } \\
\text { observed } \\
\text { cases }\end{array}$ & $\begin{array}{c}\text { No. of excess } \\
\text { attributable } \\
\text { cases }\end{array}$ & $\begin{array}{c}\% \\
\text { attributable }\end{array}$ & $\begin{array}{l}\text { No. of } \\
\text { observed } \\
\text { cases }\end{array}$ & $\begin{array}{c}\text { No. of excess } \\
\text { attributable } \\
\text { cases }\end{array}$ & $\begin{array}{c}\% \\
\text { attributable }\end{array}$ \\
\hline Esophagus & 123 & 38 & 30.9 & 110 & 35 & 31.8 & 13 & 3 & 23.1 \\
\hline Pancreas & 380 & 25 & 6.6 & 172 & 9 & 5.2 & 208 & 16 & 7.7 \\
\hline Colorectum & 1955 & 239 & 12.2 & 1107 & 191 & 17.2 & 848 & 48 & 5.7 \\
\hline Kidney & 482 & 83 & 17.2 & 326 & 54 & 16.6 & 156 & 29 & 18.6 \\
\hline Breast§ & 1545 & 124 & 8.0 & - & - & - & 1545 & 124 & 8.0 \\
\hline Endometrium & 504 & 153 & 30.4 & - & - & - & 504 & 153 & 30.4 \\
\hline Gall bladder & 55 & 11 & 20.0 & 24 & 2 & 6.5 & 31 & 10 & 32.2 \\
\hline $\begin{array}{l}\text { All associated } \\
\text { cancers } \|\end{array}$ & 5044 & 673 & 13.3 & 1739 & 290 & 16.7 & 3305 & 383 & 11.6 \\
\hline All cancers ${ }^{\star *}$ & 15836 & 673 & 4.2 & 8155 & 290 & 3.6 & 7681 & 383 & 5.0 \\
\hline \multicolumn{10}{|c|}{$\begin{array}{l}\text { *Number of cancer cases at individual cancer sites that can be attributed to overweight/obesity. } \\
\text { †Proportion of cancers at individual cancer sites attributable to overweight/obesity. } \\
\text { †Adenocarcinomas only. } \\
\text { §In postmenopausal women only (defined as cancers diagnosed at age } 55 \text { or more). } \\
\text { १ीRepresents all cancers with a known association with overweight/obesity, as listed in table. } \\
{ }^{\star *} \text { Represents all incident cancers in Alberta in } 2012 \text { in all age groups. }\end{array}$} \\
\hline
\end{tabular}

multiple myeloma. ${ }^{24}$ Hence, the burden of overweight and obesity on cancers in Alberta and the actual number of attributable cases was likely underestimated.

In separate analyse ${ }^{25}$ we estimated the burden of cancer attributable to physical inactivity. Since these 2 risk factors are highly related (i.e., a lack of physical activity leads to obesity when caloric intake surpasses the needs of the basal metabolic rate), it is likely that there is overlap in the estimated numbers of the attributable cases. Furthermore, as has been discussed in a thoughtful commentary, ${ }^{26}$ the use of the population attributable risk has limitations, and combining population attributable risks is discouraged. ${ }^{27}$

To quantify the precision of our estimates of population attributable risk, we used 95\% CIs. Although including measures of uncertainty is a strength of our study, these $95 \%$ CIs also highlight the lack of precision around our estimates ofpopulation attributable risk. For example, in men aged $55-64$, we estimated that $5.8 \%$ of pancreatic cancer could be attributable to overweight and obesity, but the $95 \%$ CI for the population attributable risk estimate ranged from $0 \%-14.4 \%$ (Appendix 1, Supplementary Table 2). As such, the lack of precision of our estimates of population attributable risk is a limitation of this analysis and should be considered when interpreting the proportion of cancers in Alberta attributable to overweight and obesity.

\section{Conclusion}

Although the estimates presented should be interpreted with caution, since they rely on several modelling assumptions and self-reported data, it is evident that many thousands of incident cases of cancer annually can be attributed to excess body weight among Canadians. Given the alarmingly high rates of overweight/obesity among adult Albertans, additional targeted prevention strategies aimed to promote weight loss and maintain a healthy body weight are recommended. These measures are likely to reduce cancer incidence as well as the burden of various other chronic diseases associated with overweight and obesity.

\section{References}

1. IARC bandbooks of cancer prevention: weight control and physical activity. Vol. 6. Lyon (France): International Agency for Research on Cancer/World Health Organization; 2002.

2. World Cancer Research Fund/American Institute for Cancer Research. Food, nutrition, physical activity and the prevention of cancer: a global perspective. Washington (DC): American Institute for Cancer Research; 2007.

3. Arnold M, Pandeya N, Byrnes G, et al. Global burden of cancer attributable to high body-mass index in 2012: a population-based study. Lancet Oncol 2015; 16:36-46.

4. Parkin DM, Boyd L. 8. Cancers attributable to overweight and obesity in the UK in 2010. Br 7 Cancer 2011;105(Suppl 2):S34-7.

5. 2012 report on cancer statistics in Alberta. Edmonton: Alberta Health Services: Surveillance \& Reporting. CancerControl Alberta; 2015. Available: www. albertahealthservices.ca/assets/healthinfo/poph/hi-poph-surv-cancer-cancer-in -alberta-2012.pdf (accessed 2014 Dec. 16).

6. Brenner DR. Cancer incidence due to excess body weight and leisure-time physical inactivity in Canada: implications for prevention. Prev Med 2014;66:131-9.

7. Grundy A, Frienenreich CM, Poirier AE, et al. A methodologic framework to evaluate the number of cancers attributable to lifestyle and environment in Alberta. CMA7 Open 2016;4:E471-8.

8. Gold EB, Bromberger J, Crawford S, et al. Factors associated with age at natural menopause in a multiethnic sample of midlife women. Am 7 Epidemiol 2001;153:865-74.

9. Palacios S, Henderson VW, Siseles N, et al. Age of menopause and impact of climacteric symptoms by geographical region. Climacteric 2010;13:419-28.

10. Canadian guidelines for body weight classification in adults. Ottawa: Health Canada; 2003.

11. Béland Y. Canadian Community Health Survey - methodological overview. Health Rep 2002;13:9-14.

12. Renehan AG, Tyson M, Egger M, et al. Body-mass index and incidence of cancer: a systematic review and meta-analysis of prospective observational studies. Lancet 2008;371:569-78. 
13. Parkin DM. 9. Cancers attributable to inadequate physical exercise in the UK in 2010. Br 7 Cancer 2011;105(Suppl 2):S38-41.

14. Renehan AG, Soerjomataram I, Tyson M, et al. Incident cancer burden attributable to excess body mass index in 30 European countries. Int 7 Cancer 2010;126:692-702.

15. Lee IM, Shiroma EJ, Lobelo F, et al. Effect of physical inactivity on major non-communicable diseases worldwide: an analysis of burden of disease and life expectancy. Lancet 2012;380:219-29.

16. Shields M, Gorber SC, Janssen I, et al. Bias in self-reported estimates of obesity in Canadian health surveys: an update on correction equations for adults. Health Rep 2011;22:35-45.

17. Luo W, Morrison H, de Groh M, et al. The burden of adult obesity in Canada. Chronic Dis Can 2007;27:135-44.

18. Neutel CI, Morrison H. Could recent decreases in breast cancer incidence really be due to lower HRT use? Trends in attributable risk for modifiable breast cancer risk factors in Canadian women. Can Fournal Public Health 2010;101:405-9.

19. Kendall BJ, Wilson LF, Olsen CM, et al. Cancers in Australia in 2010 attributable to overweight and obesity. Aust N Z J Public Health 2015;39:452-7.

20. Obesity in Canada. A joint report from the Public Health Agency of Canada and the Canadian Institute for Health Information. Ottawa: Public Health Agency of Canada; 2011.

21. Harari A, Endo B, Nishimoto S, et al. Risk of advanced papillary thyroid cancer in obese patients. Arch Surg 2012;147:805-11.

22. Lahmann PH, Cust AE, Friedenreich CM, et al. Anthropometric measures and epithelial ovarian cancer risk in the European Prospective Investigation into Cancer and Nutrition. Int 7 Cancer 2010;126:2404-15.

23. Samanic C, Gridley G, Chow WH, et al. Obesity and cancer risk among white and black United States veterans. Cancer Causes Control 2004;15:35-43.

24. Engeland A, Tretli S, Hansen S, et al. Height and body mass index and risk of lymphohematopoietic malignancies in two million Norwegian men and women. Am 7 Epidemiol 2007;165:44-52.

25. Brenner DR, Poirier AE, Grundy A, et al. Cancer incidence attributable to inadequate physical activity in Alberta in 2012. CMA7 Open. In press.

26. Rockhill B, Newman B, Weinberg C. Use and misuse of population attributable fractions. Am 7 Public Health 1998;88:15-9.

27. Morgenstern H. Attributable fractions. In: Boslaugh S, editor. Encyclopedia of epidemiology. Thousand Oaks (CA): Sage Publications; 2008.

28. Krueger H, Turner D, Krueger J, et al. The economic benefits of risk factor reduction in Canada: tobacco smoking, excess weight and physical inactivity. Can 7 Public Health 2014;105:e69-78.
Affiliations: Department of Cancer Epidemiology and Prevention Research (Brenner, Poirier, Grundy, Khandwala, McFadden, Friedenreich), CancerControl Alberta, Alberta Health Services; Department of Oncology (Brenner, Friedenreich), Cumming School of Medicine; Department of Community Health Sciences (Brenner, Friedenreich), Cumming School of Medicine, University of Calgary, Calgary, Alta.

Contributors: Christine Friedenreich and Darren Brenner were responsible for the study conception. Anne Grundy, Christine Friedenreich, Darren Brenner, Farah Khandwala and Abbey Poirier contributed substantially to the study design and interpretation of the data. Alison McFadden and Anne Grundy were responsible for acquisition of the data. Farah Khandwala completed the analysis. All of the authors contributed to preparation of the manuscript, approved the final version to be published and agreed to act as guarantors of the work.

Funding: This project was funded by the Alberta Cancer Prevention Legacy Fund. Christine Friedenreich is supported by an Alberta Innovates - Health Solutions Health Senior Scholar Award and the Alberta Cancer Foundation Weekend to End Women's Cancer Chair in Breast Cancer at the University of Calgary. Darren Brenner is supported by a Capacity Development Award in Prevention (no. 709317) from the Canadian Cancer Society Research Institute.

Acknowledgements: The authors gratefully acknowledge Laura McDougall from the Alberta Cancer Prevention Legacy Fund for her support and guidance. The authors also thank Bethany Kaposhi and Lorraine Shack from the Alberta Cancer Registry for providing cancer incidence data and the department of Data Integration, Measurement and Reporting at Alberta Health Services for enabling access to Canadian Community Health Survey data.

Supplemental information: For reviewer comments and the original submission of this manuscript, please see www.cmajopen.ca/content $/ 5 / 2 /$ E330/suppl/DC1 